\title{
Exploitation of Nanoindentation and Statistical Tools to Investigate the Behavior of Materials
}

\author{
Laid Aminallah \\ Dept of Mechanics, Mustapha Stambouli University \\ Faculty of Science and Technology \\ Mascara 29000, Algeria \\ abdaminn@yahoo.fr
}

\author{
Samir Habibi \\ Dept of Mechanics, Mustapha Stambouli University \\ Faculty of Science and Technology \\ Mascara 29000, Algeria \\ habibismr@yahoo.com
}

\begin{abstract}
The determination of the performance of materials requires the characterization of materials at scales: macro, micro and nanoscale. Among the most common experimental methods one can find the instrumented indentation test for determining the contact stiffness and contact depth and analyzing the characteristic curve by nanoindentation load on the penetration of the indentor. Through statistical processing of the experimental results, the rigidity of contact on the contact depth is investigated, depending on the indentation load, for bronze, brass and copper. A mathematical model is adopted to describe the polynomial regression by the method of least squares growth rigidity with one or more geometric parameters representative of the size of the footprint. This study allows us to identify factors that influence the rigidity of the materials examined and the sensitivity of the used indenters.
\end{abstract}

Keywords-nanoindentation; modeling; power law; contact stiffness; contact depth

\section{INTRODUCTION}

The instrumented indentation test is used to record the displacement of the indenter during the whole cycle of loading and unloading [1]. Analysis of the unloading curve leads to a contact depth value. The basic idea behind this methodology dates back to late 19th century but it the mathematical were laid the past few decades. This article is devoted to the analysis of results on various materials chosen according to the objective sought. The main objective remains to better understand and better explain the phenomena involved in the indentation. Experimental indentation tests were conducted on films of bronze, copper and brass deposited on glass slides using a nanoindentor instrumented MCT (Instrument CSM2107). For each sample, at least 20 tests were carried out with maximum load of $20 \mathrm{mN}$ to $3000 \mathrm{mN}$. The indentation tests were performed with a Vickers indenter. The load is applied at a rate of $40 \mathrm{mN} / \mathrm{min}$. The maximum load is maintained for 15 seconds and then gradually withdraws at a speed of 40 $\mathrm{mN} / \mathrm{min}$. All curves penetration strength results are exported and processed using Matlab to calculate the mechanical properties of material studied by different methods [2-4]. The end of each penetration defects were evaluated using an electron microscope field emission scanning Hitachi S-type
$4300 \mathrm{SE} / \mathrm{N}$. The measures are estimated at $150 \mathrm{~nm}$ for the Vickers indenter [5].

\section{RESULTS AND DISCUSSION}

\section{A. Analysis of the load-displacement curve}

In an instrumented indentation test, the indent diamond is pressed to the sample surface corresponding to a maximum load value at a given depth. Simultaneously the load and the displacement of the indenter is recorded and key locations are considered. $h_{\max }$ is the maximum depth reached, $h_{f}$ the residual depth after withdrawal of the indentor and $s=K * h_{c}^{n}$ is the contact depth used in calculating the hardness [1]. Calculating $h_{c}$, wherein a parameter $\varepsilon$ is introduced to take into account the deformations of the indenter impression [8] (deflection of the sink-in surfaces) is expressed by the following relationship:

$$
h_{c}=h_{\max }-\varepsilon \cdot \frac{P_{\max }}{S_{u}}
$$

To treat the results the model of [3] was applied and the calculated values are shown in Figure 1.

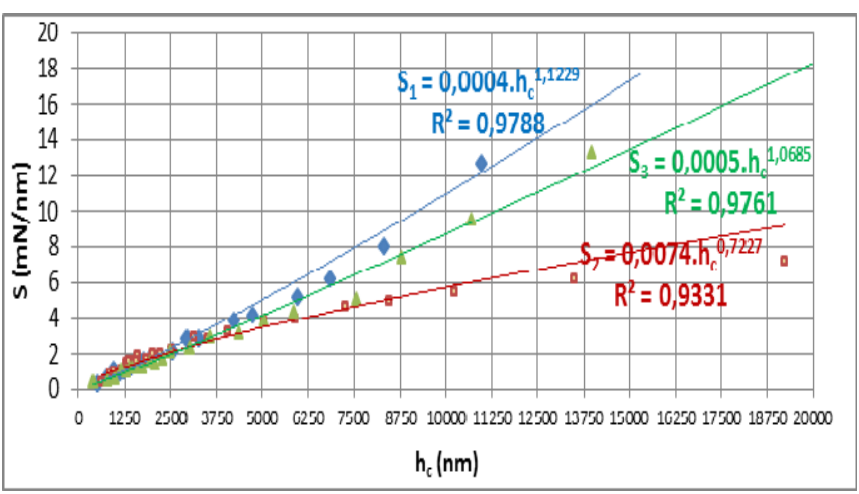

Fig. 1. Results rigidities contact vs contact depths by Vickers nanoindentation. 


\section{B. Mathematical modeling of materials}

We carried out a mathematical modeling of the three materials studied, using two indenters with different geometries: a Vickers pyramid and a spherical. Using the power law $s=K{ }^{*} h_{c}$, we expressed the rigidity of contact $S$, of the three materials depending on the contact depth of the indentor $h_{c}$.

The experimental results of the Vickers nanoindentation tests are shown in Figure 2 relating to the 21 tests considered. The curve shows good reproducibility. Following the polynomial regression by the method of least squares, we determine the expressions of $S$ vs $h_{c}$ for all three materials. We determine the values of $K$ and $\mathrm{n}$ for the three materials for the case of Vickers indenter, using the least squares method, as shown in Table I. For the case of spherical indenter, we adopt the same approach for the three materials examined, (Figure 2). The calculated values of $\mathrm{K}$ and $\mathrm{n}$ are shown in Table II.

TABLE I. THE DETERMINATION OF THE COEFFICIENTS K AND N POWER LAW

\begin{tabular}{|c|c|c|c|c|c|}
\hline Vickers & Reference & material & $\mathbf{K}$ & $\mathbf{n}$ & $\mathbf{R}^{\mathbf{2}}$ \\
\cline { 2 - 6 } indentation & 1 & Bronze & 0.0004 & 1.1229 & 0.9788 \\
\cline { 2 - 6 } & 2 & Copper & 0.0074 & 0.7227 & 0.9331 \\
\cline { 2 - 6 } & 3 & Brass & 0.0005 & 1.0685 & 0.9761 \\
\hline
\end{tabular}

TABLE II.

DETERMINING COEFFICIENTS K AND N POWER LAW

\begin{tabular}{|c|c|c|c|c|c|}
\hline \multirow{3}{*}{$\begin{array}{c}\text { Spherical } \\
\text { indentation }\end{array}$} & Reference & material & $\mathbf{K}$ & $\mathbf{n}$ & $\mathbf{R}^{\mathbf{2}}$ \\
\cline { 2 - 6 } & 1 & Bronze & 0.076 & 0.5991 & 0.9764 \\
\cline { 2 - 6 } & 2 & Copper & 0.2124 & 0.3766 & 0.7227 \\
\cline { 2 - 6 } & 3 & Brass & 0.3049 & 0.2699 & 0.8593 \\
\hline
\end{tabular}

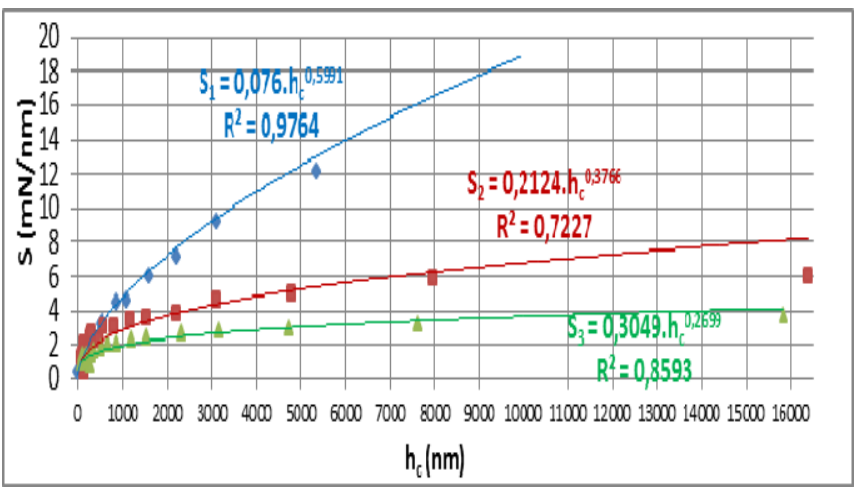

Fig. 2. Results rigidities contact vs contact depths by spherical nanoindentation

\section{Discussion}

A cloud of high density points such as the three characteristic curves merge and converge contact rigidities is evident. $\mathrm{S}$ is recognized in the interval $[0,2]$ corresponding to depths of contact between [500, 2500]. However, point (2, $2500)$ is an inflection point of the three characteristic curves, from which it is noted that:

$$
4.10^{-4} \cdot \mathrm{h}_{\mathrm{c}}{ }^{1.1229}>5 \cdot 10^{-4} \cdot \mathrm{h}_{\mathrm{c}}{ }^{1.0685}>>74 \cdot 10^{-4} \cdot \mathrm{h}_{\mathrm{c}}{ }^{0.7227} \text {. }
$$

Hence, $\mathrm{S}_{1}>\mathrm{S}_{3}>\mathrm{S}_{2}$, namely bronze contact stiffness is greater than the brass for a lower penetration, except that the brass can reach $S_{\max }>18 \mathrm{mn} / \mathrm{nm}$ for high tees penetration of the order of $20000 \mathrm{~nm}$ and the stiffness of the brass is much greater than that of copper. This means that bronze and brass are stiffer and more ductile copper. The models obtained in the case of Vickers indenter, is acceptable such as $\mathrm{R}^{2} \approx 94 \% \div 98 \%$, and tend to the perfect model. In the case of Vickers indenter $\mathrm{K}=0.0004 \div 0.0074$ and $\mathrm{n}=0.7227 \div 1.1229$, where the existence of an inverse relationship between $\mathrm{K}$ and $\mathrm{n}$ for each examined material.

It is also shown that

$$
760 \cdot 10^{-4} \cdot \mathrm{h}_{\mathrm{c}}{ }^{0.5991}>>2124 \cdot 10^{-4} \cdot \mathrm{h}_{\mathrm{c}}{ }^{0.3766}>3049 \cdot 10^{-4} \cdot \mathrm{h}_{\mathrm{c}}{ }^{0.2699}
$$

Hence $\mathrm{S}_{1}>>\mathrm{S}_{2}>\mathrm{S}_{3}$. But only $\mathrm{R}^{2}$ Bronze enables the reproducibility of the experiment. By cons, $\mathrm{R}^{2}$ of copper and brass is not statistically significant to allow repeatability of experiments and thus, is not predictive. In all cases, the bronze has the best rigidity of contact, whether for Vickers indenter or spherical. But his modeling shows that the constant $\mathrm{K}$ for Vickers cases:

$$
\mathrm{K}_{\mathrm{V}}=(1 / 190) \cdot \mathrm{Ks}(\mathrm{Ks} \text { : for the spherical case); }
$$

However, the exponent of the power law $n_{v}=1.8743 \cdot n_{s}$. This explains the effect of the geometrical correlation factor between the two types of geometry indenters.

\section{Expression of $K$ and $n$ according to the indentation loading}

We would like to assign a mathematical formulation of $\mathrm{K}$ and $\mathrm{n}$ varying in ascending order the maximum load $\mathrm{P}_{\max }$ for each indentation test, as indicated by the following graphs (Figures 3-6). A relatively similar mechanical behavior of both materials bronze and brass so that a convergence in the charging interval $[0,3000] \mathrm{mN}$ is recognized at the loading point $3000 \mathrm{mN}$ when $\mathrm{K}_{1}=\mathrm{K}_{3}=0.00075$ and a tendency to very close up $10000 \mathrm{mN}$ curve with a spread of $\mathrm{K}<0.0008$. However, copper adopts a behavior quite different insofar as the trend of the curve believes in a very narrow range of around $[0,2250] \mathrm{mN}$ with a peak of the constant $\mathrm{K}$ in $[0,0005]$ with the exception of two focal points recorded on the first $\mathrm{K}_{1}=\mathrm{K}_{2}=400$ and the second $\mathrm{K}_{3}=\mathrm{K}_{2}=800$ in a reduced interval $[0,900] \mathrm{mN}$.

It is shown that the coefficient $\mathrm{n}$ is a special strain hardening coefficient varies in the range of $[0.95,1.15]$. The coefficients of bronze and brass namely $\mathrm{n}_{1}=\mathrm{n}_{3}=1.05$ for a load $3750 \mathrm{mN}$. And a tendency of relatively constant curve with a reduced gap of $\mathrm{n}<0.1$ in the range [3000, 10000] $\mathrm{mN}$. Against by an inversely proportional relationship is found between $n$ and $\mathrm{P}_{\max }$ for copper and a sudden drop of $\mathrm{n}$ from $[1.75,10000]$ for a varying indentation load of $[0,10000] \mathrm{mN}$.

Further, it seems that there is a proportional relationship between $\mathrm{K}_{1}$ and $\mathrm{K}_{2}$ vs $\mathrm{P}_{\max }$, namely that for bronze gentle growth is noticed between $(49.2,0.00006)$ and the maximum point $(10023.19,0.0010)$. But for copper indentation loading effect on the coefficient $\mathrm{K}$ is very pronounced, in so far as there is a peak $(10023.19,0.0074) . \mathrm{K}_{1}=\mathrm{K}_{2}=0.00045$ for a loading $184.07 \mathrm{mN}$ and a critical load point for copper since he believes 
abruptly. Finally the existence of an inverse relationship between $n_{1}$ and $n_{2}$ vs Pmax and $n_{1}=n_{2}=1.25$ for a maximum indentation load equal to $127.56 \mathrm{mN}$ is evident. On the other hand, $\mathrm{n}$ for brass develops sensitivity to the intensity of the load, since noticed a proportional relationship between the $n_{3}$ vs $\mathrm{P}_{\max }$. Table III summarizes the results obtained by nanoindentation of the three materials, expressing $\mathrm{K}$ and $\mathrm{n}$ vs $\mathrm{P}_{\max }$. Modeling coefficients and exponents of the power law of the three materials studied as a function of the variation of the indenting force to the residual imprint of the specimens are summarized in Table III.

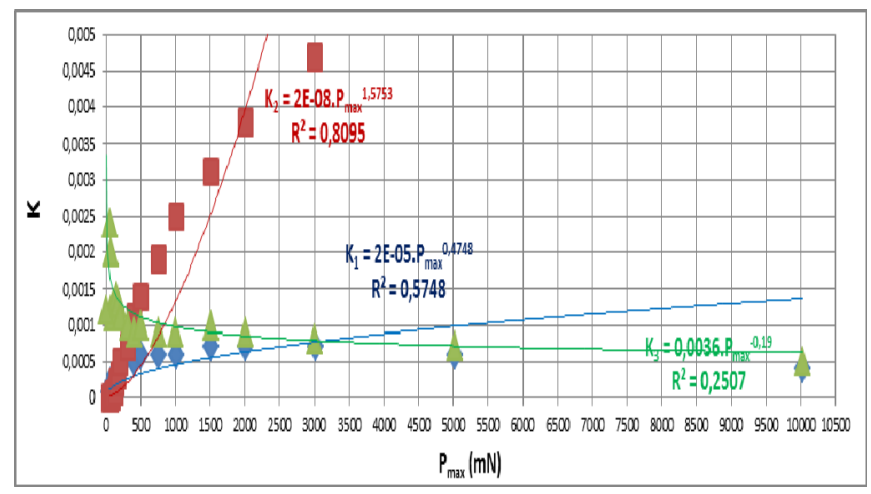

Fig. 3. Relationship of $\mathrm{K}$ as a function of the maximum indentation load.

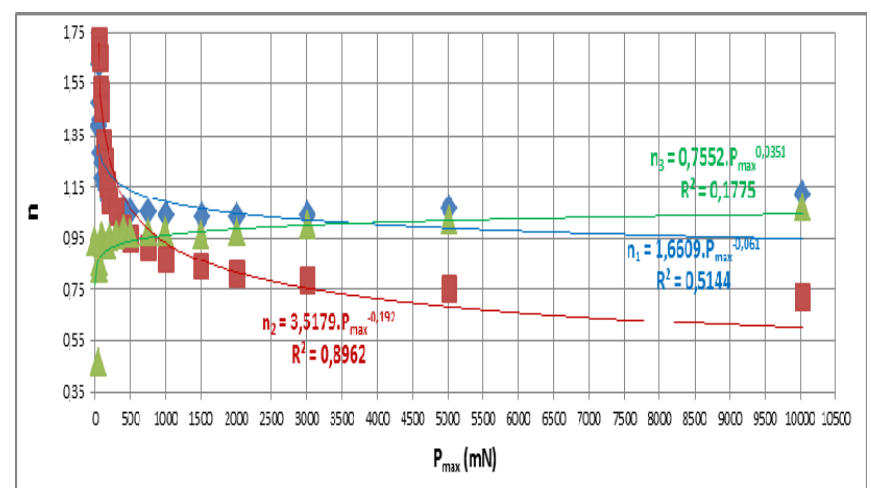

Fig. 4. Relation of $\mathrm{n}$ as a function of the maximum indentation load.

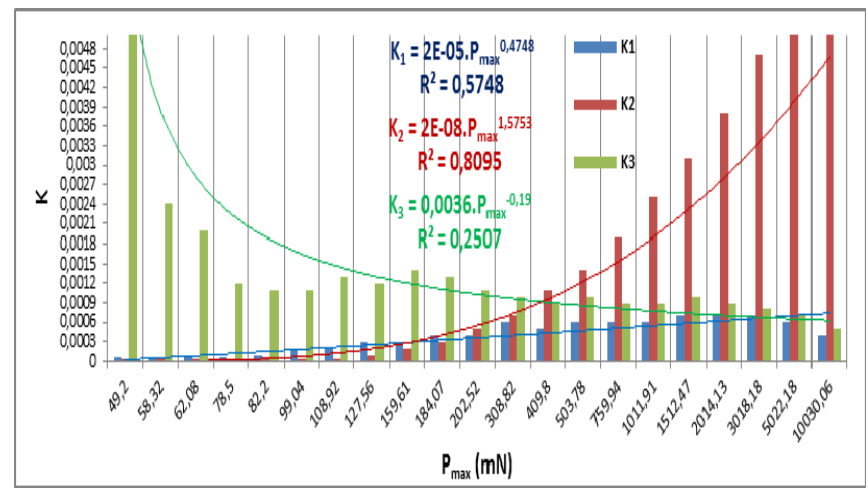

Fig. 5. The coefficients $\mathrm{K}$ of the power law vs the indentation loading.

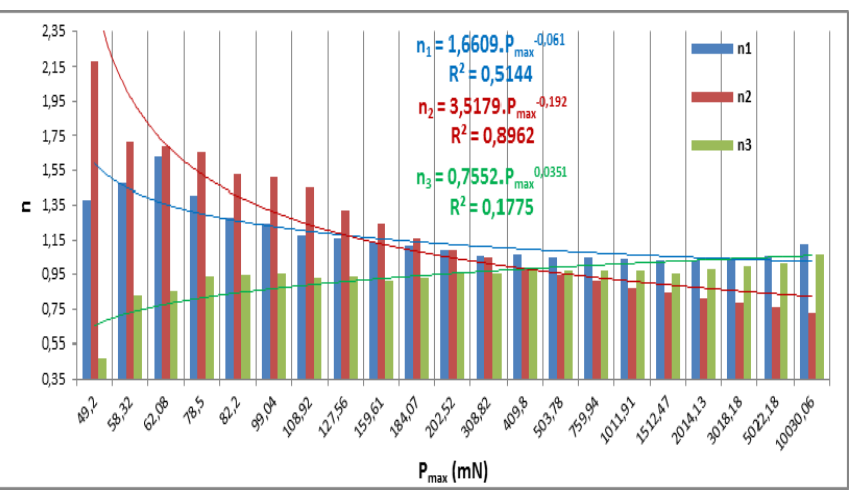

Fig. 6. Factors $\mathrm{n}$ power law vs the indentation loading.

TABLE III.

expressions of $\mathrm{k}$ and $\mathrm{n}$ vs $F_{\max }$

\begin{tabular}{|c|c|c|c|}
\hline Reference & Material & $\mathbf{K}$ & $\mathbf{n}$ \\
\hline 1 & Bronze & $2 \mathrm{E}-05 . \mathrm{P}_{\max }{ }^{0.4748}$ & $1.6609 . \mathrm{P}_{\max }{ }^{-0.061}$ \\
\hline 2 & Copper & $2 \mathrm{E}-08 . \mathrm{P}_{\max }{ }^{1.5753}$ & $3.5179 . \mathrm{P}_{\max }{ }^{-0.192}$ \\
\hline 3 & Brass & $0.0036 . \mathrm{P}_{\max }{ }^{-0.19}$ & $0.7552 . \mathrm{P}_{\max }{ }^{0.0351}$ \\
\hline
\end{tabular}

\section{CONCLUSION}

The use of statistical methods and the least squares method, allowed the characterization of three nonferrous materials: bronze, brass and copper. Using mathematical tools, the power law of the mechanical behavior of the reviewed materials by instrumented nanoindentation was investigated. The rigidity of the contact material essentially depends on the following factors: the nature of the material, the type of nanoindentor geometry and the intensity of the indentation force applied to the imprint. The power law also allows the modeling of its coefficients and exponents treated as stiffness coefficients and the hardening respectively, which are sensitive to the intensity of the load by nanoindentation. The nature of the material also influences the sensitivity, i.e. the chemical composition of different materials examined.

\section{ACKNOWLEDGMENTS}

The authors wishes to thank Professor Noureddine Benseddiq for having offered the opportunity to realize indentation tests Polytechnic IUT of Lille1/ France. The authors gratefully acknowledges Professor Didier Chicot advice for relevance and quality of leadership within the IUT Polytechnic in the research laboratory of Lille1 / France.

\section{REFERENCES}

[1] S. Habibi, A. Ziadi, A. Megueni, "Modeling a Small Punch Testing Device”, Eng. Technol. Appl. Sci. Res., Vol. 4, No. 2, pp. 612-617, 2014

[2] W. C. Oliver, G. M. Pharr, "An improved technique for determining hardness and elastic modulus using load and displacement sensing indentation measurements", J. Mat. Res., Vol. 7, No. 6, pp. 1564-1583, 1992

[3] A. H. W. Ngan, H. T. Wang, B. Tang, K. Y. Sze, "Correcting power-law viscoelastic effects in elastic modulus measurement using depth-sensing indentation", Int. J. Solids. Struct., Vol. 42, No. 5-6, pp. 1831-1846, 2005

[4] D. Chicot, F. Roudet, V. Lepingle, G. Louis, "Strain gradient plasticity tostudy hardness behaviour of magnetite (FE3O4) under multicyclic indentation", J. Mater. Res., Vol. 4, No. 3, pp. 749-759, 2009 
[5] M. R. Van Landingham, "Review of Instrumented Indentation", J. Res. Nat. Inst. Stand. Techn., Vol. 108, pp. 249-265, 2003.

[6] J. M. Antunes, J. V. Fernandes, L. F. Menezes, B. M. Chaparro, “A new approach for reverse analyses in depth-sensing indentation using numerical simulation”, Acta. Mater., Vol. 55, pp. 69-81, 2007

[7] T. C. Ovaert, B. R. Kim, J. Wang, "Multi-parameter models of the viscoelastic/plastic mechanical properties of coatings via combined nanoindentation and non-linear finite element modeling”, Prog. Org. Coat., No. 47, pp. 312-323, 2003

[8] Y. T. Cheng, C. M. Cheng, "Scaling, dimensional analysis, and indentation measurements", Mater. Sci. Eng. R., Vol. 44, pp. 91-149, 2004

[9] G. Kermouche, J.L. Loubet, J.M. Bergheau, "Extraction of stress-strain curves of elastic-viscoplastic solids using conical/pyramidal indentation testing with application to polymers”, Mech. Mater., Vol. 40, pp. 271283, 2008

[10] L. Anand, N. M. Ames, "On modeling the micro-indentation response of an amorphous polymer", Int. J. Plast., Vol. 22, pp. 1123-1170, 2006

[11] O. Sahin, O. Uzun, U. Kolemen, N. Ucar, "Analysis of ISE in dynamic hardness measurements of $\beta$-Sn single crystals using a depth-sensing indentation technique", Mater. Charact., Vol. 59, pp. 729-736, 2008

[12] G. M. Pharr, A. Bolshakov, "Understanding nanoindentation unloading curves”, J. Mater. Res., Vol. 17, No. 10, pp. 2660-2671, 2002 